\title{
书院特色发展：双院协同育人一一山西农业大学信息学院箕 城书院为例
}

\author{
王靖 ${ }^{1}$ 徐艳娜 ${ }^{2}$ \\ 1 山西农业大学信息学院 2 安徽农业大学 \\ DOI:10.32629/er.v3i7.2997
}

\begin{abstract}
[摘要] 随着独立院校的不断发展,山西农业大学信息学院以 “商科教育+完满教育+通识教育十专业教 育”四位一体的育人模式, 在已有的学院制模式下, 实行 “书院制”改革, “双院制”学校逐渐成型。在 双院管理平台中以 “学生活动高质量, 学生管理高效能” 为宗旨, 以提高学生综合素质为目标, 以学生队 伍建设为驱动力, 实施素质教育, 与时俱进, 以激发学生领导力, 培养学生组织管理能力为特色。本文以山 西农业大学信息学院箕城书院为例, 结合目前书院特色发展主题, 探究在双院协同育人发展模式下, 如何 更好地开展双院活动, 激发书院学生团队领导力, 提高书院学生团队综合能力的培育路径探究。
\end{abstract}

[关键词] 完满教育; 双院协同育人; 书院制; 书院学生团队

为更好的引导学生成长, 以见证学 生改变为目标, 在已有的学院制模式下, 山西农业大学信息学院于 2017 年实行

“书院制”改革, 为山西首家双院制大学, “双院制” 逐渐成型。书院立足学生, 探究 “双院” 模式下培养学生的合理方 式, 以 “ $1+1>2$ ” 开展建设工作, 搭建双 院融合平台, 共同促进学生成长, 独树一 帜的育人模式, 创新的教育理念指引下, 建立新的教育体制, 实施新的教学方法, 学校以完满教育为特色教育模式, 完满 教育是指课堂教学以外的一切提高素 质、培养能力、锻造人格、强健体魄的 活动, 包括社团活动、公益服务、竞技体 育、艺术实践等, 完满教育以“提高学生、 发展学生、锻炼学生” 为理念, 双院模式 的成立, 同时也推动 “完满教育” 发展, 为培养学生的个性和促进学生全面发展 提供了更为广阔的空间, 优化学生知识 结构、提高学生综合能力、形成学生较 强社会适应力的有效途径。

\section{1 双院融合背景下书院学生团}

\section{队培育路径发展建设}

我国建立书院的各高校普遍采取书 院和学院协作并存的 “双院” 制形式, 书院负责综合素质和人格养成, 学院负
责专业教学和学术研究, 这使得学生具 有了双重身份, 书院和学院横向交融, 纵 向贯通、相辅相成、协调配合进行人才 培养。

1.1 “双院” 协同合作 共促特色平 台发展

山西农业大学信息学院现共有6大 书院, 箕城书院、青藤书院、无边书院、 太行书院、杏花书院、三达书院, 每个书 院配备了管理团队、导师团队、学生团 队 “三支队伍”, 全方位打造书院社区。 为进一步强化书院与院系、各单位的协 同合作, 促进学生的全面成长和发展, 书 院与各教学单位通过交流与互动, 不断 加强联系, 实现共建、共育、共享及深度 融合。“双院制”进一步实现“协同育人”, 共同构筑 “书院生态圈”, 帮助提升学生 领导力, 彰显学校育人特色。山西农业大 学信息学院 20 个教学单位同 6 个书院签 署全面合作协议活动组织、指导评价、 场地共享、文化培育、项目孵化、理论 研究等各方面全方位展开合作。

1.2 “双院” 协同合作 助力学生 成长

为践行人才培养新路径, 推动 “双 院” 协同育人新模式。山西农业大学信
息学院各院系与各书院坚持以学生成长 为中心, 通过交流互动、不断加强联系, 将专业知识与完满活动相结合, 积极推 进完满教育联动融合, 帮助学生全面发 展。箕城书院围绕核心其领导力 “思辨 力”与合作院系积极沟通交流, 助力学生 成长。实验实训中心、素质拓展中心分 别与箕城书院签订合作协议, 开展双院 导师联培活动, 包括“为什么关系中出现 了问题, 我们更容易相互指责”, “学生 干部角色定位与执行能力提升” 等专题 培训活动, 助力学生团队全面发展。

1.3 “双院” 协同合作 促进学生团 队发展

箕城书院学生会有 8 个职能部门, 分 别是: 场地服务部、平面设计部、品牌 营销部、新闻编辑部、社区服务部、文 化培育部、项目服务部、综合服务部。 为积极贯彻 “联动融合” 的发展主题, 进一步推动 “双院融合”, 充分发挥 “ $1+1>2$ ” 的核心力量, 提升学生综合素 养, 培养书院学生团队学习能力, 箕城书 院学生会团队与院系学生会团队积极联 动。分别与淬炼商学院学生会团队、经 济与管理学院学生会团队开展学生团队 双院联培计划。每学期与淬炼商学院、 
经济与管理学院学生会团队开展双院学 生会联培计划。包括, 双院各职能学生会 部门培训交流, 共赴山西省图书馆参观 学习, “新商科・新思维・新融合” 品牌 建设论坛服务等, 通过不同形式合作, 双 院学生团队进行工作交流学习, 齐分享, 共进步。

1.4 “双院” 协同合作 提升学生团 队能力

完满教育理念是以培养完整的人为 核心和育人目标, 通过开展丰富多彩的 校园文化活动促进学生的全面发展和综 合能力提升。书院制是完满教育的延伸, 书院特色文化要以丰富多彩的形式使目 标、受众和步骤过程互相衔接, 指导学生 开展科学实验、政策分析、审美鉴赏、 社会实践、文化交流等活动。书院教育 的落脚点就在于 “活动”, “活动” 是载 体、箕城书院以培养学生 “思辨力” 为 核心, 坚持 “低门监、乐参与、重体验” 的活动原则一直在探索实践, 书院学生 团队是书院教育中重要成员之一, 通过 参与设计、组织、开展各类活动来提升 学生综合能力。为培育书院特色文化, 给学生提供更多的教育资源, 箕城书院 在学校联动融合发展背景下与合作院系 一起搭建具有 “思辨力” 特色的活动平 台。在双院协同育人模式下, 双院学生团 队齐聚力, 共同组织活动, 完成工作内容, 提升团队能力, 充分发挥 “完满+专业”、 “学院+书院” 的协同创新。箕城书院与 食品环境学院一起联合举办 “时尚 - 生 活 - 家” 养成计划, 学生通过组织参与讲 座、沙龙、体验、实践等不同形式的活 动设计, 围绕活动关注时尚潮流和有质 量的生活方式, 并从中萃取它的本质和 真义, 共有五个子活动, 双院学生会团队 共同负责, 来打造专属自己的 “时尚” 模
板。箕城书院与经济与管理学院联合举 办 “逻辑开发潜能, 推理揭秘真相” 首届 剧本杀推理活动、“品阅文化经典・悦享 诗意青春” “ $1+1$ ” 文化传承周系列活 动。以学生丰富体验与强化实践为目的, 在组织参与活动中不断相互学习, 交流, 提升学生团队综合能力。

2 双院协同育人环境下, 书院 制学生团队问题及培育方式探究

现在中国内地大学的书院都是作为 一种嵌入式的组织结构, 书院打破了大 学原有的组织架构和运行模式, 加之探 索时间短, 对新型书院特征、运行规律认 识不够等, 书院与学院之间的双院矛盾 使书院学生团队在书院特色发展环境: “双院” 协同育人模式中存在问题更为 突出。

2.1双院沟通平台和合作平台不够 健全

目前学校没有完善建立双院交流制 度, 制度的缺失导致信息沟通不流畅, 书 院学生会团队与院系团队一般情况下都 是各干各的, 双院老师很少召开联席会 议共同探讨学生会人才培养方案以及学 生团队共同存在的问题, 学院也很少安 排学生会团队与书院学生会进行对接, 沟通平台与合作平台不健全。

2.2 书院与学院分工不清, 定位不明

在人才培养中, 对学院与书院各自 到底应该承担哪些责任不明确, 书院与 学院分工不清, 定位不明, 导致学生团队 在合作中也会产生分歧。书院侧重于学 生团队领导力培养, 学院为学生团队综 合能力提升, 在一起合作完成活动及学 生团队联培计划中, 双方侧重点不同。

2.3 书院学生团队缺少专业导师 指导

在双院协同育人的环境下, 书院制
学生团队缺少专业导师指导, 在双院融 合平台搭建以后, 培训老师为院系老师, 主题讲座次数较少, 在书院制学生团队 中渗入层面较浅, 学习内容较为有限, 缺 少专业导师引导, 导致在双院联培计划 中, 书院制学生团队表现欠缺。在双院协 同育人环境下我们首先要加强对书院学 生队伍的定位, 指导书院学生团队科学 规划工作内容, 围绕书院核心领导力开 展工作。对学生团队进行书院文化培养, 要求学生自我管理、自我服务、自我监 督为工作原则, 围绕书院核心领导力工 作和培养学生干部自觉成才意识开展双 院合作活动。其次, 在双院协同育人环境 中, 要不断完善书院各项制度和机制, 加 强书院学生团队建设, 请专业指导老师 定期对学生干部进行工作培训, 提高学 生干部的综合素质, 确保学生会干部具 有典型示范作用。然后调动书院学生会 团队工作积极性, 与学院各部门积极配 合, 才能稳步推进联动融合、协同育人各 项工作。最后, 构建双院协同育人机制, 是培养人才, 促进书院学生团队成长的 重要路径之一, 为实现学院, 书院协同育 人, 应该统筹设计第一课堂, 第二课堂, 建立人才培养平台方案, 推进书院学生 团队发展, 在专业教育与书院特色文化 的培养下, 提升书院学生团队的综合素 质发展, 共同进步。

\section{[参考文献]}

[1]罗峻,王枫。学院书院双院管理模 式下的教学管理新探索 [J]. 时代教 育,2015,(21):157.

[2]李会春.书院建设在中国: 制度与 张力[J].教育学术月刊,2012,(4):50-58.

[3]张鸽,袁否, 都长江. “双院制” 协 同育人模式下沟通机制研究 [J].教育现 代化,2018,5(29):113-114+360. 